\title{
Ni and Ni-Fe perovskite for catalytic abatement of tar
}

\author{
C. Gervasio, E. Grieco and G. Baldi \\ Department of Science of Materials and Chemical Engineering \\ Politecnico di Torino \\ C.so Duca degli Abruzzi, 24 - 10129 Torino (Italy) \\ Phone number:+0039 011564 4695, Fax number:+0039 011564 4699, e-mail: cristina.gervasio@polito.it, \\ enrico.grieco@polito.it, giancarlo.baldi@polito.it
}

\begin{abstract}
$\mathrm{LaNiO}_{3}$ and $\mathrm{LaNi}_{0,3} \mathrm{Fe}_{0,7} \mathrm{O}_{3}$ have been tested as catalyst for tar cracking reaction. They have been prepared, characterised and tested in a laboratory plant at $500-600^{\circ} \mathrm{C}$. Naphthalene and nexadecane were employed as representatives tar compounds. The tests on $\mathrm{LaNiO}_{3}$ show that it has a very high activity but XRD characterisation reveals that the catalyst is not stable in the reducing atmosphere produced during the cracking tests. XRD and EDS analysis show that there is carbon deposition on catalyst that mechanically blocks the passage of flow. The addition of iron in the catalyst structure is effective only for the n-exadecane cracking reaction. In the tests with naphthalene $\mathrm{LaNi}_{0,3} \mathrm{Fe}_{0,7} \mathrm{O}_{3}$ does not solve the problem of carbon deposition on catalyst and hence its deactivation.
\end{abstract}

\section{Key words}

Biomass gasification, Tar removal, Catalytic cracking, Perovskite oxides, Regeneration

\section{Introduction}

Renewable energies will undoubtedly increase their importance in global energy supplies. Among the renewable untraditional sources, biomass probably will give the greater contribution. Gasification is one of the most important techniques to produce energy from biomass. The experience shows that the production of electricity using steam produced by combustion of wood leads to very low yields (17-18\%). Gasification instead leads to significantly higher yields and offers many advantages. Gasification produces syn-gas $\left(\mathrm{H}_{2}, \mathrm{CO}, \mathrm{CO}_{2}\right)$ that can be used either for direct energy production (gas turbines, engines, combined cycles) and for liquid fuels synthesis (such as diesel, naphtha, GPL and petrols through Fischer-Tropsch process). In particular, integrated gasification combined cycle (IGCC) allows the production of electrical energy with high performance. Another advantage is the reduction in the costs related to pollutants treatment.
One of the major problems to be solved in the application of this technology is the hot gas cleanup from tar. Tar is a complex mixture of hydrocarbons and oxygen containing compounds having a molecular weight higher than benzene; they are condensable at room temperature. The composition of tar depends on pyrolysis conditions [1]. Tar is an undesired product because it leads to the formation of aerosol and the deposition inside the process equipments such as gasifier, engine or turbine system that causes mechanical problems [2]. Tar elimination can be made afterwards the gasifier (secondary methods) through scrubbing operation with $\mathrm{H}_{2} \mathrm{O}$ or organic liquids, thermal or catalytic cracking. Nowadays these methods give good performances but they allow the total elimination of tar with a very high economic charge. For this reason the treatments inside the gasifier are progressively gaining the attention of the operators. In fact a convenient choice of the operational parameters, appropriate modifications in the project of the gasifier and the use of a suitable catalyst inside the bed of the gasifier can assign to secondary methods prevailingly the role of polishing with a clear economic saving. In fact to produce liquid fuels (Fischer-Tropsch process) it is necessary to reduce the concentration of tar in the syngas to very low values $\left(10^{-3}\right.$ or $\left.10^{-4} \mathrm{~g} / \mathrm{Nm}^{3}\right)$.

Scrubbing operation is economically unattractive and leads to environmental pollution problems. Thermal cracking occurs at higher temperatures than those normally employed for catalytic cracking. Catalytic cracking of tar is a more promising way to eliminate tar; furthermore energetic enhancement can be achieved by the conversion of tar into syn-gas [3]. Our goal is to find a catalyst sufficiently active, resistant to deactivation and not much expensive.

Actually there are many types of catalysts used for this application: minerals like calcined rocks, olivine, clay minerals and iron ores or synthetic catalysts like zeolites, activated alumina, alkali metal-based or transition metal based catalysts. In particular Ni-based catalysts are 8-10 times more active than dolomite, are able to attain complete tar elimination at $900^{\circ} \mathrm{C}$ and to increase the yield of $\mathrm{CO}_{2}$ and $\mathrm{H}_{2}$. The problem is their rapid 
deactivation due to sulphur and high tar content in the feed [4]. As suggested by S. Rapagnà et al. [5] to limit the problem of rapid deactivation we have chosen to use Ni-based perovskite type oxides. In fact perovskites are well defined structures with high metallic dispersion and a strong interaction between the elements included in the structure that limit the sintering of the active specie and carbon build-up. To inhibit the coking is necessary that the clusters of the active metal remain of a dimension smaller than a certain critical size [6]. Perovskites are characterised by oxygen mobility and they are also stable in a non-stoichiometric structure that improve their catalytic activity. $\mathrm{Ni}$ and $\mathrm{Ni}-\mathrm{Fe}$ perovskites were tested in this work.

\section{Experimental}

We have carried out our tests in a laboratory reactor. Two gas chromatographs were used to analyze cracking reaction products. Naphthalene and n-exadecane were chosen as representative tar compounds; according to Roberto Coll et al. [7] naphthalene is one of the most stable tar compounds. The perovskites were prepared by thermal low-temperature decomposition of $\mathrm{La}, \mathrm{Ni}$ and $\mathrm{Fe}$ nitrates. The catalysts were characterised by BET, XRD and EDS analyses. The first catalyst tested was $\mathrm{LaNiO}_{3}$. XRD analysis after the tests showed that $\mathrm{LaNiO}_{3}$ is not stable in the reducing atmosphere produced during cracking reaction and the presence of an high amount of carbon is also confirmed by EDS analysis. To try to limit the problem of reduction we have introduced iron in the perovskite structure.

\section{A. Preparation of perovskite catalysts}

$\mathrm{LaNiO}_{3}$ and $\mathrm{LaNi}_{0,3} \mathrm{Fe}_{0,7} \mathrm{O}_{3}$ polycrystalline powders were prepared by thermal low-temperature decomposition of $\mathrm{La}, \mathrm{Ni}$ and $\mathrm{Fe}$ nitrates.

$\mathrm{La}\left(\mathrm{NO}_{3}\right)_{3} \cdot 6 \mathrm{H}_{2} \mathrm{O}, \quad \mathrm{Ni}\left(\mathrm{NO}_{3}\right)_{2} \cdot 6 \mathrm{H}_{2} \mathrm{O}$ and $\mathrm{Fe}\left(\mathrm{NO}_{3}\right)_{3} \cdot 9 \mathrm{H}_{2} \mathrm{O}$ were firstly dissolved in a double weight of distilled water and then added of $10 \%$ in weight (with respect to the nitrates weight) of pure glycerol.

Then the solution was put in a porcelain crucible and heated at $200^{\circ} \mathrm{C}$ for 1 hour in order to complete the decomposition of metal nitrates assisted by the organic reducing agent (glycerol). The resulting crispy solid was then heated at $700^{\circ} \mathrm{C}$ for 3 hours to allow the crystallization of the perovskite phase. The catalyst was removed from the crucible and gently ground in an agate mortar.

\section{B. Catalysts characterisation}

The catalysts have been characterised by powder X-Ray Diffraction (XRD) on a X'Pert Philips diffractometer using the Bragg Brentano camera geometry and the $\mathrm{Cu}$ $\mathrm{K} \alpha$ incident radiation.

$\mathrm{XRD}$ analysis have been carried out before the cracking tests to assess the formation of the desired phase and also after the cracking tests to evaluate the stability of the catalyst or the formation under the reaction conditions of other phases different from the original one.
BET surface areas have been determined by nitrogen adsorption at $77 \mathrm{~K}$ in a Micrometrics ASAP $2010 \mathrm{M}$ instrument. The samples were degassed in vacuum for at least $4 \mathrm{~h}$ at $180{ }^{\circ} \mathrm{C}$ before the analysis.

The catalysts have been also characterised after the cracking tests with EDS.

\section{Description of the plant}

The cracking tests have been performed in a laboratory plant (figure 1). During the tests a nitrogen flow of 50 $\mathrm{ml} / \mathrm{min}$ is used as carrier gas. It passes through a tar evaporator to achieve the saturation. Water is added through a syringe pump and then vaporized. The amount of water added is three times higher than that required to have no carbon deposition at equilibrium condition. The flow passes through a damping tank and then in a reactor placed in an oven.

\section{Gas analysis}

Reaction products are analysed with two different gas chromatographs by sampling online. The first one (Varian 3400) is connected to the reactor by a heated line and analyzes the concentration of residual tar. The connection line is maintained at a temperature higher than the condensation one. The second one (Micro-GC 24 channel system Varian CP-4900) analyzes the concentration of light gases produced by cracking reaction such as $\mathrm{H}_{2}, \mathrm{O}_{2}, \mathrm{CO}, \mathrm{CO}_{2}, \mathrm{CH}_{4}$, etc.

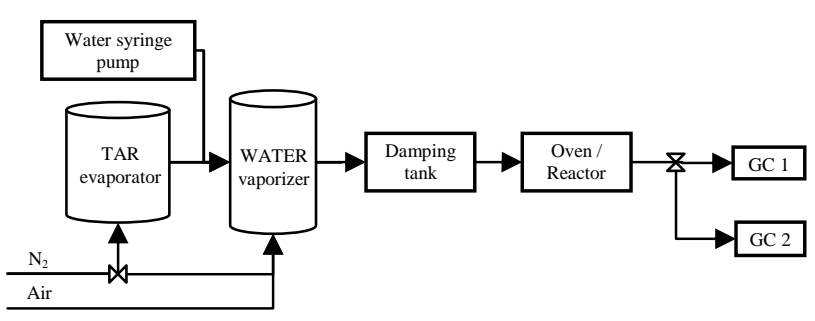

Fig. 1. The plant

\section{Results and discussion}

\section{A. Instability of $\mathrm{LaNiO}_{3}$ catalysts}

The first catalyst tested was $\mathrm{LaNiO}_{3}$. XRD analysis before the test confirmed the formation of the desired phase (figure 2). The BET surface area was found to be equal to $11 \mathrm{~m}^{2} / \mathrm{g}$. For all tests we put in the reactor $1 \mathrm{~g}$ of catalyst powder diluted with 3 times in volume of $\mathrm{SiO}_{2}$. At a low concentration of naphthalene such as $5 \mathrm{~g} / \mathrm{Nm}^{3}$ it allows a total conversion during 70 hours with a reactor temperature of $500^{\circ} \mathrm{C}$ and during 200 hours with a reactor temperature of $600^{\circ} \mathrm{C}$. Instead with a naphthalene concentration of $35 \mathrm{~g} / \mathrm{Nm}^{3}$ conversion quickly decreases from $90 \%$ in the first 3 hours to $25 \%$ after 50 hours with a reactor temperature of $600^{\circ} \mathrm{C}$. Without any positive result, at the end of this test we have tried to regenerate the catalyst. We used $12,4 \mu \mathrm{l} / \mathrm{min}$ of water and $37 \mathrm{ml} / \mathrm{min}$ of air in a $\mathrm{N}_{2}$ flow of $30 \mathrm{ml} / \mathrm{min}$ for $16 \mathrm{~h}$ at a reactor temperature of $600^{\circ} \mathrm{C}$ and for $7 \mathrm{~h}$ at $700^{\circ} \mathrm{C}$. Figure 2 
provides a comparison between the different tests. For all the tests the WHSV (weight hourly space velocity) was equal to $3748 \mathrm{~h}^{-1}$. Figure 4 shows that in all these cases carbon balance was not closed, with an error progressively increasing till $40 \%$. XRD analysis after the tests showed that the initial perovskite structure was destroyed with the formation of $\mathrm{Ni}, \mathrm{LaO}_{3}$ and $\mathrm{La}_{2} \mathrm{O}_{2} \mathrm{CO}_{3}$ (figure 5). So $\mathrm{LaNiO}_{3}$ is not stable in the reducing atmosphere produced during cracking reaction and carbon is (partially) chemically bounded to the catalyst structure. Another part of carbon is depositated on the catalyst as coke; although EDS analysis does not provide a precise measure of the quantity of carbon in the sample, in figure 6 we can see that the pick of carbon has the highest intensity. So the presence of an high amount of carbon is also confirmed by EDS analysis. The catalyst is extremely active but easily affected by coking. Besides, all the tests were interrupted because of plugging of the reactor; probably there is formation of soot that occludes the packed bed.

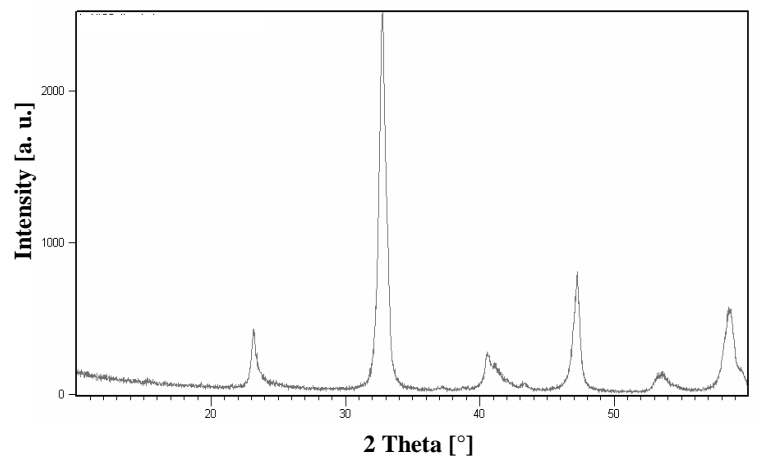

Fig. 2. XRD analysis of $\mathrm{LaNiO}_{3}$ before the cracking test

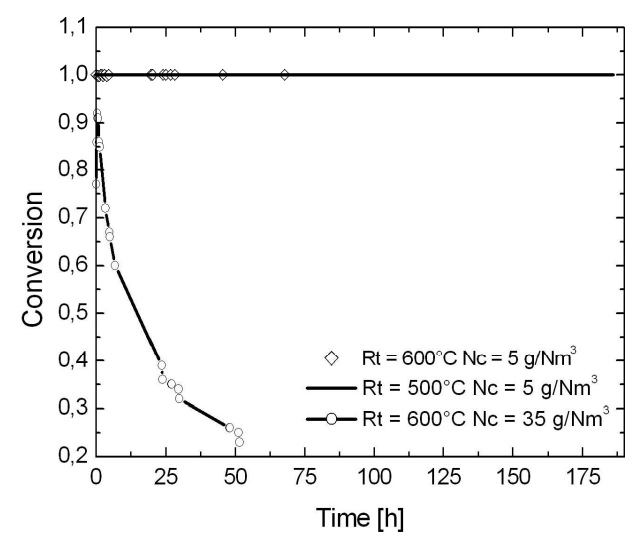

Fig. 3. Trend of the conversion of naphthalene at different condition of reactor temperature $(\mathrm{Rt})$ and concentration of naphthalene (Nc) in the tests with $\mathrm{LaNiO}_{3}$

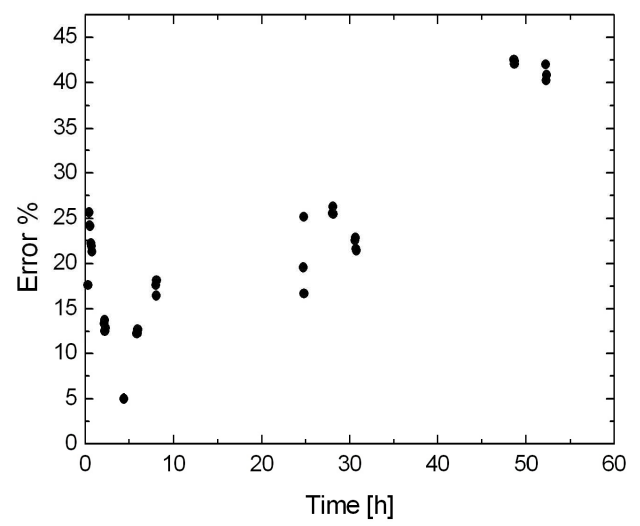

Fig. 4. Error $\%$ on the closure of carbon balance in the tests with $\mathrm{LaNiO}_{3}$

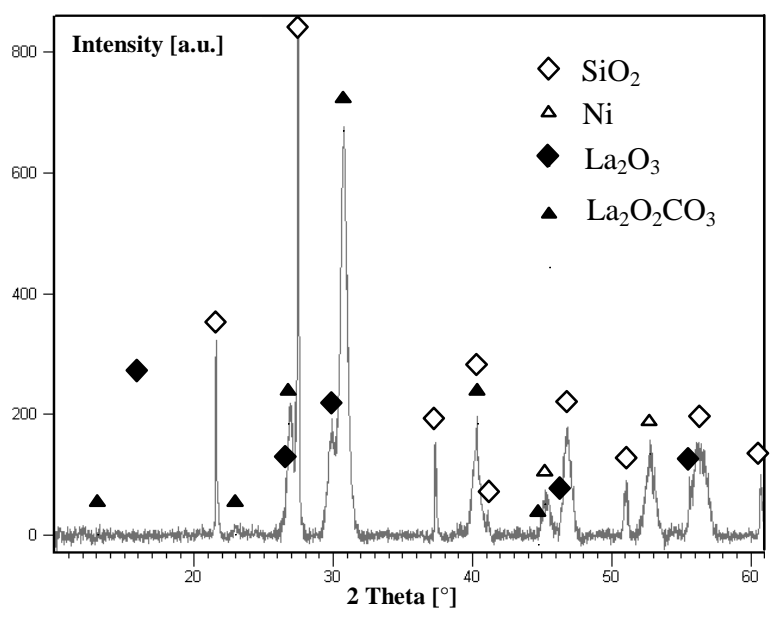

Fig. 5. XRD analysis of $\mathrm{LaNiO}_{3}$ after the cracking test

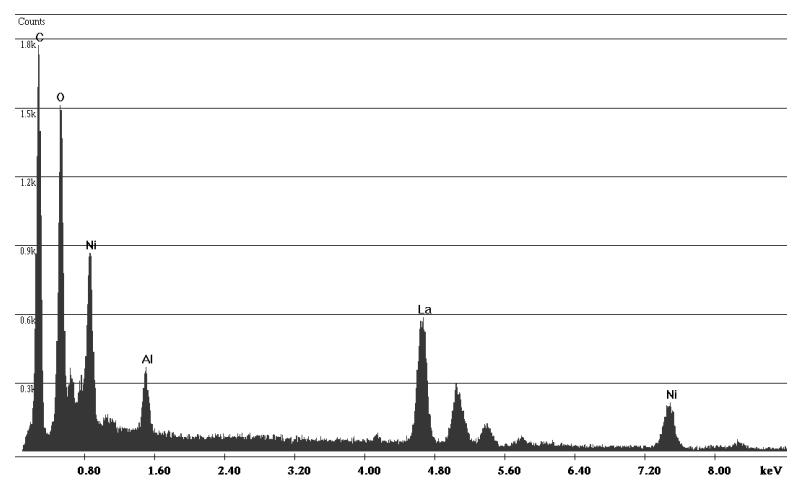

Fig. 6. EDS analysis of $\mathrm{LaNiO}_{3}$ after the cracking test

\section{B. Performances of $\mathrm{LaNi}_{0.3} \mathrm{Fe}_{0.7} \mathrm{O}_{3}$ catalysts}

To try to limit the problem of reduction of nickel we have introduced iron in the perovskite structure. On the basis of the tests made by Proviender at al. [8] we have chosen to test $\mathrm{LaNi}_{0.3} \mathrm{Fe}_{0.7} \mathrm{O}_{3}$ because it seems to provide a good compromise between catalytic activity and stability under reaction conditions. XRD analysis on the fresh sample confirmed the formation of the desired phase (figure 7). 
BET surface area was $8,57 \mathrm{~m}^{2} / \mathrm{g}$. We put in the reactor 1 $\mathrm{g}$ of catalyst powder diluted with 3 times in volume of $\mathrm{SiO}_{2}$. Naphthalene concentration was $5 \mathrm{~g} / \mathrm{Nm}^{3}$. Figure 8 shows the trend of conversion in relation to the time and to the variation of the reactor temperature. The temperature of the reactor was put initially at $500^{\circ} \mathrm{C}$ and maintained for $2,5 \mathrm{~h}$. As naphthalene conversion was very low, the reactor temperature was risen at $600^{\circ} \mathrm{C}$. At this temperature the catalyst allowed a total naphthalene conversion. After $90 \mathrm{~h}$ the temperature was restored at $500^{\circ} \mathrm{C}$. For the first hours the conversion remained high in contrast with the behaviour recorded at the beginning of the test and it went down to $20 \%$ in 50 hours. The catalyst seems to have undergone a sort of activation in the period in which the reaction occurred at $600^{\circ} \mathrm{C}$. However the catalyst rapidly lost its activity.

Another test was conduced with only $0,3 \mathrm{~g}$ of catalyst corresponding to a value of WHSV of $12493 \mathrm{~h}^{-1}$ and reaching the temperature of $600^{\circ} \mathrm{C}$ without staying at $500^{\circ} \mathrm{C}$. The conversion went down from $100 \%$ to $20 \%$ in $50 \mathrm{~h}$ (figure 9). The catalyst was regenerated for $3,5 \mathrm{~h}$ excluding the naphthalene evaporator from the circuit and with the same water flow rate. The test was repeated after regeneration. At the beginning the conversion was total but it returned to $20 \%$ in 2 hours. In both cases XRD spectrums (figure 10-11) show that the perovskite structure is maintained with a little shift of the picks to the left with respect to the picks of the synthesized perovskite (corresponding to $\mathrm{LaNi}_{\mathrm{x}} \mathrm{Fe}_{1-\mathrm{x}} \mathrm{O}_{3}$ with $\mathrm{x}<0,3$ ). There is also a little amount of metallic nickel because is visible its principal pick that is more evident for the second test (figure 11).

The carbon balance does not close for high values of conversion (figure 12-13). Probably there is carbon deposited that cover the active sites.

This catalyst was also tested with n-exadecane as representative tar compound with a concentration of 5 $\mathrm{g} / \mathrm{Nm}^{3}$ and a reactor temperature of $500^{\circ} \mathrm{C}$. As shown in figure 14 the conversion remains stable between $60-70 \%$ for 200 hours. The carbon balance is closed (figure 15). Perovskite structure remains stable (figure 16).

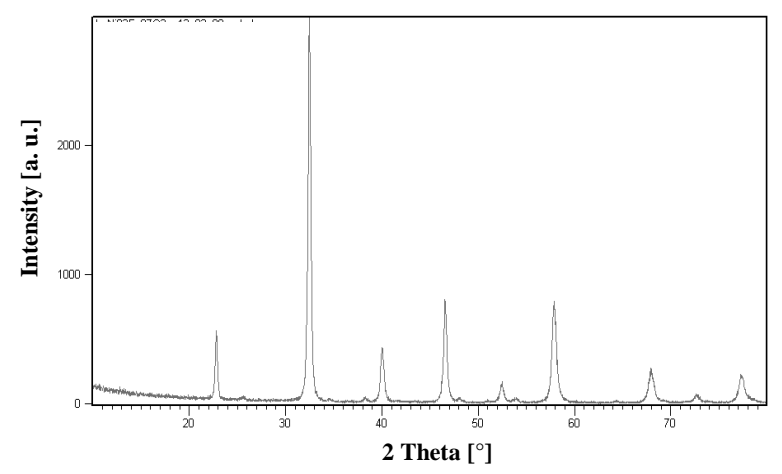

Fig. 7. XRD analysis of $\mathrm{LaNi}_{0,3} \mathrm{Fe}_{0,7} \mathrm{O}_{3}$ before the cracking test

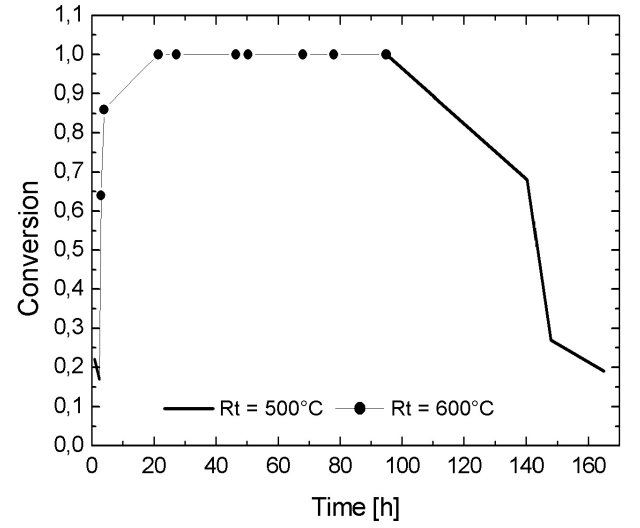

Fig. 8. Conversion of naphthalene in relation to the time and to the variation of the reactor temperature $(\mathrm{Rt})$ for the first cracking test with $\mathrm{LaNi}_{0,3} \mathrm{Fe}_{0,7} \mathrm{O}_{3}$

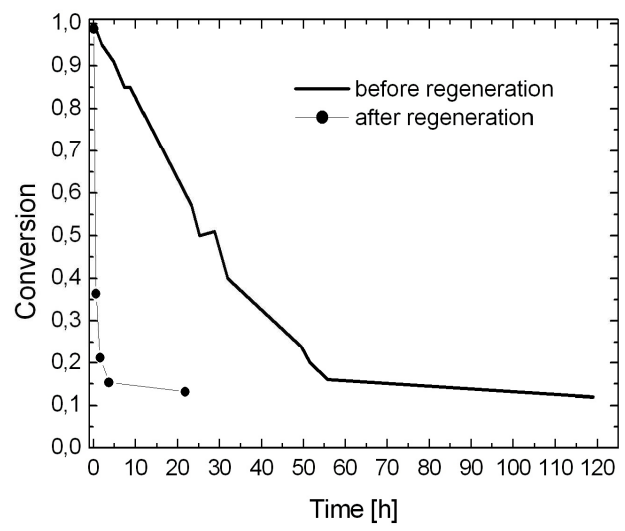

Fig. 9. Conversion of naphthalene in relation to the time at a reactor temperature $\mathrm{Rt}=600^{\circ} \mathrm{C}$ for the second cracking test with $\mathrm{LaNi}_{0,3} \mathrm{Fe}_{0,7} \mathrm{O}_{3}$

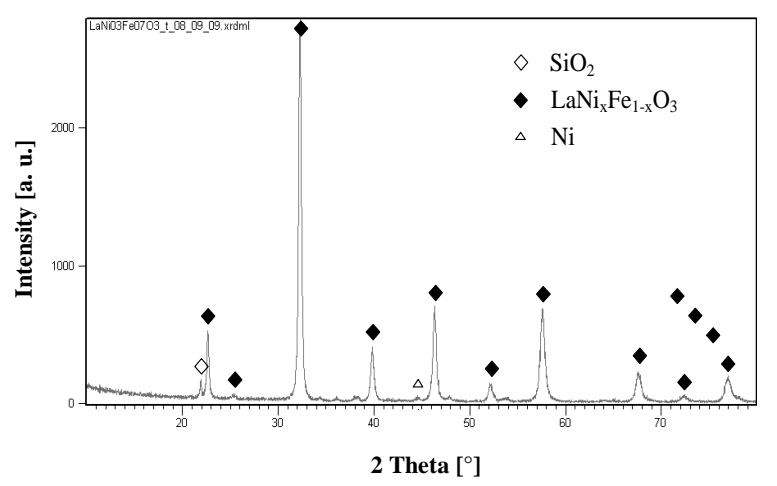

Fig. 10. XRD analysis of $\mathrm{LaNi}_{0,3} \mathrm{Fe}_{0,7} \mathrm{O}_{3}$ after the first cracking test with $\mathrm{LaNi}_{0,3} \mathrm{Fe}_{0,7} \mathrm{O}_{3}$ 


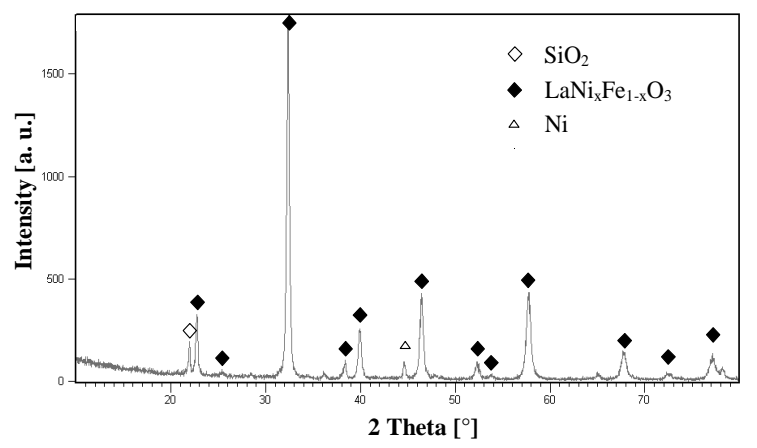

Fig. 11. XRD analysis of $\mathrm{LaNi}_{0,3} \mathrm{Fe}_{0,7} \mathrm{O}_{3}$ after the second cracking test with $\mathrm{LaNi}_{0,3} \mathrm{Fe}_{0,7} \mathrm{O}_{3}$

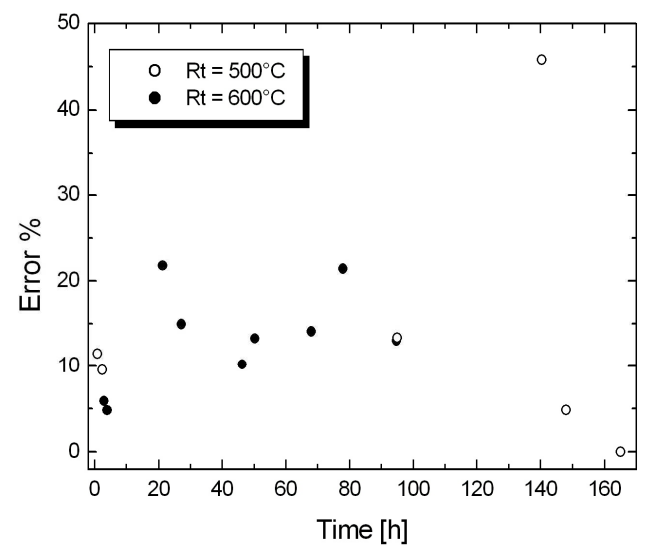

Fig. 12. Error $\%$ on the closure of carbon balance for the first cracking test with $\mathrm{LaNi}_{0,3} \mathrm{Fe}_{0,7} \mathrm{O}_{3}$

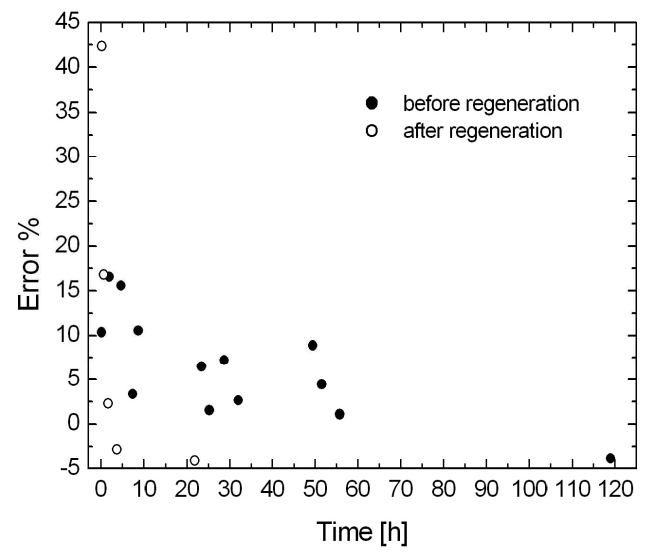

Fig. 13. Error $\%$ on the closure of carbon balance for the second cracking test with $\mathrm{LaNi}_{0,3} \mathrm{Fe}_{0,7} \mathrm{O}_{3}$

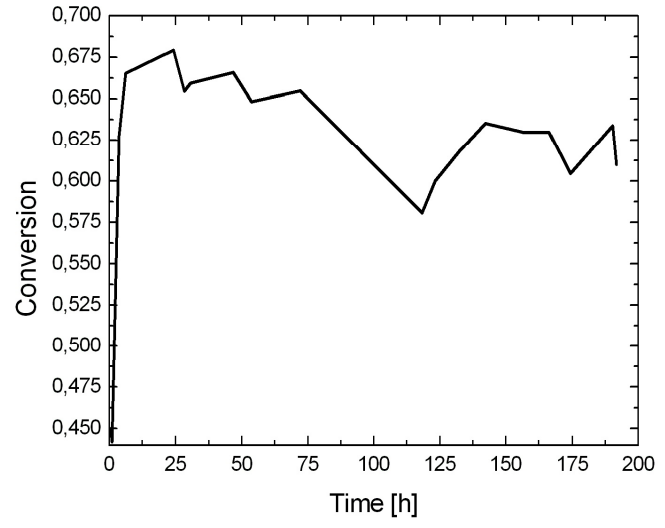

Fig. 14. Conversion of $\mathrm{n}$-exadecane in relation to the time at a reactor temperature $\mathrm{Rt}=500^{\circ} \mathrm{C}$ with $\mathrm{LaNi}_{0,3} \mathrm{Fe}_{0,7} \mathrm{O}_{3}$

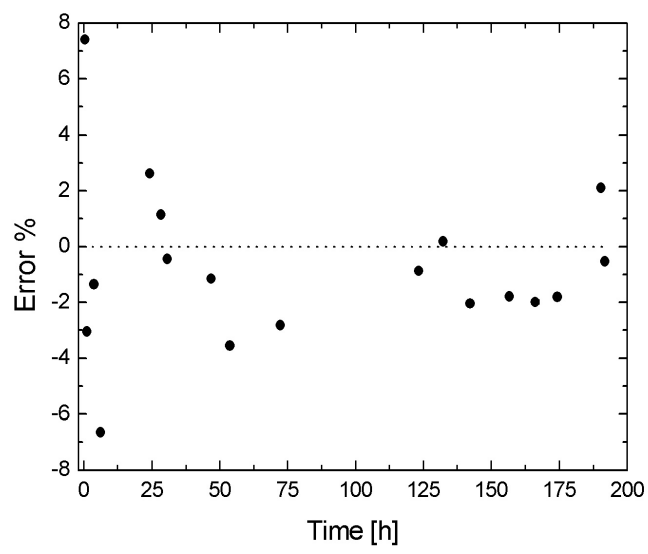

Fig. 15. Error $\%$ on the closure of carbon balance for the nexadecane cracking test with $\mathrm{LaNi}_{0,3} \mathrm{Fe}_{0,7} \mathrm{O}_{3}$

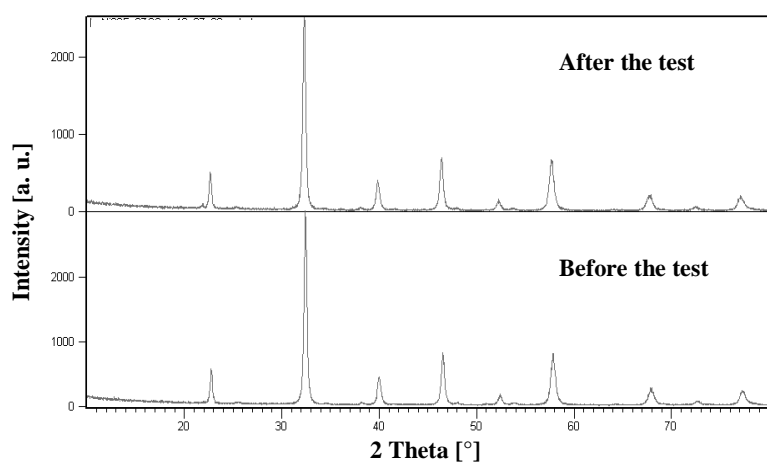

Fig. 16. Comparison between XRD analysis of $\mathrm{LaNi}_{0,3} \mathrm{Fe}_{0,7} \mathrm{O}_{3}$ before and after the n-exadecane cracking test

\section{Conclusion}

Two nickel based perovskites have been prepared by thermal low-temperature decomposition of $\mathrm{La}, \mathrm{Ni}$ and $\mathrm{Fe}$ nitrates and characterised by means of XRD, BET and EDS. They have been tested as catalysts for tar cracking reaction to provide the cleanup of gas produced by gasification. $\mathrm{LaNiO}_{3}$ has a very high activity but XRD analysis have revealed that is not stable in the reducing atmosphere produced during the tests. Carbon deposition 
on catalyst mechanically blocked the passage of flow. The addition of iron in the perovskite structure leads to a higher stability but does not solve the problem of carbon deposition on catalyst and hence its deactivation. $\mathrm{LaNi}_{0,3} \mathrm{Fe}_{0,7} \mathrm{O}_{3}$ has a better behaviour in terms of stability and deactivation in the test with n-exadecane than in the tests with naphthalene. In fact the structure of naphthalene make easier to form graphitic layers. Further investigations should be made to understand the mechanism of deactivation and the possibility of regeneration. Other elements rather than iron should be inserted in the catalyst structure to stabilise the structure against reduction.

\section{References}

[1] T.A. Milne, N. Abatzoglou, R.J. Evans, Biomass gasifier "tars": their nature, formation and conversion. National Renewable Energy Laboratory (NREL), reports NREL/TP-57025357, Colorado, 1998.

[2] J. Srinakruang, K. Sato, T. Vitidsant, K. Fujimoto, "Highly efficient sulfur and coking resistance catalysts for tar gasification with steam”, Fuel 2006, Vol. 85, pp. 2419-2426.

[3] Umberto Arena, Ugo Leone, Maria Laura Mastellone, "Recupero di energia e materia da rifiuti solidi: i processi le tecnologie, le esperienze, le norme", AMRA S.c. a r.l. Sezione Politiche Territoriali, Facoltà di Ingegneria e Facoltà di Scienze Ambientali, Seconda Università di Napoli, p. 178

[4] Z. Abu El- Rub, E. A. Bramer, G. Brem, "Review of Catalysts for Tar Elimination in Biomass Gasification", Ind. Eng. Chem. Res. 2004, Vol. 43, pp. 6911-6919.

[5] S. Rapagnà, H. Provendier, C. Petit, A. Kiennemann, P. U. Foscolo, "Development of catalysts suitable for hydrogen or syn-ges production from biomass gasification", Biomass \& Bioenergy 2002, Vol. 22, pp. 377-388.

[6] J. Guo, H. Lou, Y. Zhu, X. Zheng, "La-based perovskite precursors preparation and its catalytic activity for $\mathrm{CO}_{2}$ reforming of $\mathrm{CH}_{4}$ ", Materials Letters 2003, Vol. 57, pp. 44504455.

[7] R. Coll, J. Salvao', X. Farriol, D. Montane', "Steam reforming model compounds of biomass gasification tars: conversion at different operating conditions and tendency towards coke formation", Fuel processing Technology 2001, Vol. 74(1), pp. 19-31.

[8] H. Proviender, C. Petit, C. Estournès, S. Libs, A. Kiennemann, "Stabilisation of active nickel catalysts in partial oxidation of methane to synthesis gas by iron addition", Applied Catalysis A: General 1999, Vol. 180, pp. 163-173. 